\title{
Circulating ERBB3 levels are inversely associated with the risk of overweight- related hypertension: a cross-sectional study
}

Lijun Zhu ${ }^{1,2 \dagger}$, Zhengmei Fang ${ }^{1,2+}$, Yuelong Jin ${ }^{1,2}$, Weiwei Chang ${ }^{1,2}$, Mengyun Huang ${ }^{1}$, Yan Chen ${ }^{1,2^{*}}$ and Yingshui $\mathrm{YaO}^{1,2,3^{*}}$

\begin{abstract}
Background: Hypertension and overweight are independent risk factors for cardiovascular disease, and overweight increase the risk of developing high blood pressure. ERBB3( also known as HER3) plays a considerable role in the development of cardiovascular diseases. However, the effect of ERBB3 levels in hypertensive overweight patients is unknown. The aim of this study was to assess the association between ERBB3 levels and hypertension in overweight Chinese patients.
\end{abstract}

Methods: We evaluated the height,weight, blood pressure, biochemical indicators, and ERBB3 levels in 128 Chinese adults aged 33-79 years. Plasma ERBB3 levels were assessed by the enzyme-linked immunosorbent assay, and body mass index(BMI) was calculated as body weight divided by height squared. Participants were allocated into three groups according to blood pressure and BMI: healthy control (CNT, $n=31$; normotensive and non-overweight), hypertension ( $\mathrm{HT}, n=33$; hypertension and non-overweight), and hypertension with overweight $(\mathrm{HTO}, n=64$; hypertension and overweight). Statistical significance was defined as a two-tailed $P<0.05$.

Results: There was no significant difference in mean ERBB3 levels among the three groups, although a linear decrease from CNT $(1.13 \pm 0.36)$, HT $(1.03 \pm 0.36)$, to HTO $(0.84 \pm 0.26 \mathrm{ng} / \mathrm{mL})$ was observed in men $(P=0.007)$. Among the drinking population, the ERBB3 level was significantly reduced in the HTO group as compared with those of the CNT and HT groups ( $0.76 \pm 0.23$ versus $1.18 \pm 0.37$ and $1.20 \pm 0.30$, respectively). ERBB3 levels were negatively correlated with diastolic blood pressure in men $(r=-0.293, P=0.012)$, smoking $(r=-0.47, P=0.004)$, and drinking $(r=-0.387, P=0.008)$. BMI in men and among drinkers, and uric acid among drinkers were negatively correlated with ERBB3 levels. Multivariate conditional logistic regression showed that plasma ERBB3 levels were associated with a reduced risk of HTO in men [odds ratio (OR) 0.054; $95 \%$ confidence interval (CI): 0.007-0.412) and drinkers (OR 0.002; $95 \%$ Cl: 0.000-0.101).

\footnotetext{
* Correspondence: bingyan-1209@163.com; yingshuiyao@126.com

'Lijun Zhu and Zhengmei Fang contributed equally to this work.

1 Department of Epidemiology and Biostatistics, School of Public Health

Wannan Medical College, No. 22, Wenchang Road, Anhui 241002 Wuhu,

China

Full list of author information is available at the end of the article
}

(c) The Author(s). 2021 Open Access This article is licensed under a Creative Commons Attribution 4.0 International License, which permits use, sharing, adaptation, distribution and reproduction in any medium or format, as long as you give appropriate credit to the original author(s) and the source, provide a link to the Creative Commons licence, and indicate if changes were made. The images or other third party material in this article are included in the article's Creative Commons licence, unless indicated otherwise in a credit line to the material. If material is not included in the article's Creative Commons licence and your intended use is not permitted by statutory regulation or exceeds the permitted use, you will need to obtain permission directly from the copyright holder. To view a copy of this licence, visit http://creativecommons.org/licenses/by/4.0/. The Creative Commons Public Domain Dedication waiver (http://creativecommons.org/publicdomain/zero/1.0/) applies to the data made available in this article, unless otherwise stated in a credit line to the data. 
Conclusions: ERBB3 may contribute to the pathogenesis of hypertension in overweight patients, with BMI, gender, and drinking all potentially modulating the process.

Keywords: ERBB3, Hypertension, Overweight, Body mass index

\section{Background}

Hypertension is a condition in which the blood vessels have persistently raised pressure,and is one of the most pressing public health challenges. The global burden of hypertension has been growing in recent decades, largely driven by population growth, changes in lifestyle, and aging [1]. From 1975 to 2015, the number of adults with high blood pressure increased from 594 million to 1.13 billion, with a particularly large increase in lowincome and middle-income countries[2]. Based on data from 451,755 Chinese individuals, the prevalence of hypertension among adults was $27.9 \%$, and was similar among men (28.6\%) and women (27.2\%) [3]. Previous studies have shown that the prevalence of hypertension may be accounted for by increasing body mass index (BMI) [4]. Indeed, a high BMI (i.e., overweight or obese) is a major risk factor for several chronic diseases, including diabetes, cardiovascular diseases, and hypertension [5]. Epidemiological studies have shown an association between BMI and blood pressure both normal-weight and overweight patients [6]. Previous studies have reported that BMI is strongly associated with hypertension in northern Chinese adults [7], and could explain $45 \%$ of the age-adjusted increase in diastolic blood pressure (DBP) over the study period in an Indians population [8].

The ERBB (also known as HER) family of membranebound tyrosine kinase receptors comprises ERBB1, ERBB2, ERBB3, and ERBB4, which activate potent signalling pathways that mediate cell proliferation or differentiation[9]. Unlike other ERBB family members, the function of ERBB3 (HER3) has been investigated less frequently because its intracellular kinase domain is thought to be an inactive pseudokinase, thereby relying on interactions with other ERBB partners [10]. To date, ERBB3 has been widely used as a tumour marker; however, it was recently reported to be associated with cardiovascular diseases [11].

$E R B B 3$ mRNA expression levels on the surface of monocytes were reported to be inversely correlated with tumor necrosis factor alpha in subjects with heart failure but not in human subjects without heart failure[12]. In addition, the brown fat-enriched secreted factor NRG4 has been proposed as a potential target to treat obesityassociated disorders, which primarily signals through ERBB3 to regulate diverse biological processes [13]. Emerging evidence suggests that dysregulation of ERBB3 is important in mediating hyperglycaemia-induced vascular dysfunction [14]. A case-control study showed that $E R B B 3$ genetic polymorphisms are associated with the pathogenesis of coronary artery disease [15]. Moreover, recent animal studies showed that transient receptor potential vanilloid 4 (TRPV4) ion channels, a major $\mathrm{Ca}^{2+}$ influx pathway in endothelial cells, contributes to obesity-induced hypertension [16]. Moreover, G proteincoupled receptors regulate TRPV4 activity in the vasculature by mediating ERBB family transactivation [17]. Thus, we hypothesized that the ERBB3 may participate in the process that leads to the occurrence and development of hypertension in the and overweight context.

Given that ERBB3 may play a considerable role in the development of cardiovascular diseases, the aim of this study was to assess the relationship between plasma ERBB3 levels and hypertension in overweight Chinese adults, and to provide the basis for the pathogenesis of overweight-related hypertension.

\section{Methods \\ Study Subjects}

The subjects were recruited via the Health Management Center and Physical Examination Center at Yijishan Hospital of Wannan Medical College from July 2019 to August 2019. According to the 'Seventh report of the joint national committee on prevention, detection, evaluation, and treatment of high blood pressure', hypertension is generally defined as a systolic blood pressure (SBP) of $\geq 140 \mathrm{mmHg}$ or a DBP of $\geq 90 \mathrm{mmHg}$ or the use of antihypertensive medications. For adults, BMI China reference standard defines overweight as a $\mathrm{BMI} \geq$ 24. Accordingly, in this study, the healthy control group (CNT) was defined as both normotensive and BMI $<24$, the hypertension group (HT) was defined as both hypertensive and $\mathrm{BMI}<24$, the hypertension with overweight group (HTO) was defined as both hypertension and $\mathrm{BMI} \geq 24$. Finally, 128 adults (aged 33-79 years), including 31 in the CNT group, 33 in the HT group, and 64 in the HTO group, were included in this study for assessing the association between plasma ERBB3 levels and hypertension with in the context of overweight.

The study was approved by the Ethics Committee of the First Affiliated Yijishan Hospital of Wannan Medical College (Wuhu, China). Written informed consent was obtained from all participants. 


\section{Data collection}

At physical examination, all subjects were measured for height and weight, and blood pressure. BMI was calculated as body weight $(\mathrm{kg})$ divided by height squared $\left(\mathrm{m}^{2}\right)$. A well-trained research staff member measured blood pressure once using an electronic sphygmomanometer with the participant in the sitting position after at least $5 \mathrm{~min}$ of rest. Subjects were classified as smokers (including current and ex-smokers) or non-smokers, and as drinkers (including current and ex-drinkers) or nondrinkers.

\section{Biochemical analyses}

Blood samples were obtained from the subjects after an overnight fast for at least $10 \mathrm{~h}$. Total cholesterol (TC), triglyceride (TG), high-density lipoprotein cholesterol (HDL-C), low-density lipoprotein cholesterol (LDL-C), glucose (GLU), and uric acid (UA) were measured using standard methods at the physical examination institution.

\section{Enzyme-linked immunosorbent assay (ELISA)}

Three millilitre venous blood samples were collected and centrifuged at $3000 \mathrm{rpm}$ for $10 \mathrm{~min}$. The supernatant was collected using a micropipette and stored in at $-80{ }^{\circ} \mathrm{C}$ until use. The plasma samples were then thawed at room temperature for ELISA using a commercial kit ( CUSABIO,Catalogue No.: No. CSB-
EL007765HU) according to the manufacturer's instructions. All measurements were repeated twice to calculate the average of parallel samples.

\section{Statistical analysis}

Statistical analysis was performed using SPSS software (version 18.0, SPSS Inc., Chicago, IL, USA). The normality assumption of the data was tested using the Kolmogorov-Smirnov test. Quantitative data are expressed as mean \pm standard deviation (SD) and categorical data are expressed as frequencies $(n, \%)$. The differences in variables among the groups were determined by one-way analysis of variance (ANOVA) or the chi-square test. Pearson's correlation coefficient was used for assessing correlations of normally distributed data. Multiple unconditional logistic regression analysis with effect sizes [odds ratios (ORs) and $95 \%$ confidence intervals $(C I s)]$ was applied to estimate the risk of hypertension with and without overweight after adjusting for potential confounding factors. Statistical significance was defined as a twotailed $P<0.05$.

\section{Results}

\section{Characteristics of the study participants}

As shown in Table 1, there were no differences in age; TC, LDL-C, HDL-C, and GLU levels; or the distribution of sex and drinking status among the three

Table 1 Characteristics of the study participants among CNT, HT and HTO groups

\begin{tabular}{|c|c|c|c|c|c|c|}
\hline Characteristic & Group & CNT $(n=31)$ & $\mathrm{HT}(n=33)$ & HTO $(n=64)$ & $F / X^{2}$ & $P$ \\
\hline \multirow[t]{2}{*}{ Gender } & Male & $18(58.1)$ & $22(66.7)$ & $32(50.0)$ & 2.512 & 0.285 \\
\hline & Female & $13(41.9)$ & $11(33.3)$ & $32(50.0)$ & & \\
\hline Age (year) & & $60.32 \pm 5.82$ & $63.67 \pm 8.35$ & $62.61 \pm 8.69$ & 1.476 & 0.232 \\
\hline \multirow[t]{2}{*}{ Blood pressure $(\mathrm{mmHg})$} & SBP & $122.84 \pm 13.27$ & $148.94 \pm 15.86^{*}$ & $147.23 \pm 14.26^{*}$ & 35.19 & $<0.001$ \\
\hline & $\mathrm{DBP}$ & $74.29 \pm 9.58$ & $83.00 \pm 9.62^{*}$ & $83.59 \pm 10.97^{*}$ & 9.18 & $<0.001$ \\
\hline $\mathrm{TC}(\mathrm{mmol} / \mathrm{L})$ & & $4.86 \pm 0.90$ & $4.44 \pm 0.82$ & $4.51 \pm 0.97$ & 1.961 & 0.145 \\
\hline $\mathrm{TG}(\mathrm{mmol} / \mathrm{L})$ & & $1.61 \pm 0.78$ & $1.43 \pm 0.58$ & $2.03 \pm 1.10^{*} \#$ & 5.354 & 0.006 \\
\hline $\mathrm{HDL}-\mathrm{C}(\mathrm{mmol} / \mathrm{L})$ & & $1.53 \pm 0.36$ & $1.51 \pm 0.38$ & $1.40 \pm 0.24$ & 2.414 & 0.094 \\
\hline LDL-C(mmol/L) & & $2.59 \pm 0.73$ & $2.28 \pm 0.68$ & $2.18 \pm 0.82$ & 2.966 & 0.055 \\
\hline UA(umol/L) & & $360.01 \pm 88.18$ & $329.27 \pm 80.75$ & $385.63 \pm 95.21 \#$ & 4.327 & 0.015 \\
\hline GLU(mmol/L) & & $5.08 \pm 0.95$ & $5.45 \pm 0.94$ & $5.45 \pm 1.14$ & 1.430 & 0.243 \\
\hline $\mathrm{BMI}\left(\mathrm{kg} / \mathrm{m}^{2}\right)$ & & $21.43 \pm 1.73$ & $21.40 \pm 1.90$ & $26.71 \pm 2.51^{*} \#$ & 91.753 & $<0.001$ \\
\hline $\operatorname{ERBB3}(\mathrm{ng} / \mathrm{ml})$ & & $1.00 \pm 0.43$ & $1.01 \pm 0.35$ & $0.92 \pm 0.37$ & 0.792 & 0.455 \\
\hline \multirow[t]{2}{*}{ Current smoker } & Yes & $12(38.7)$ & $14(42.4)$ & 10(15.6) & 10.003 & 0.007 \\
\hline & No & 19(61.3) & 19(57.6) & $54(84.4)$ & & \\
\hline \multirow[t]{2}{*}{ Current drinker } & Yes & $12(38.7)$ & $12(36.4)$ & $22(34.4)$ & 0.174 & 0.917 \\
\hline & No & 19(61.3) & $21(63.6)$ & $42(65.6)$ & & \\
\hline
\end{tabular}

CNT healthy control group, $H T$ hypertension group, $H T O$ hypertension with overweight group, $B M I$ body mass index, SBP systolic blood pressure, $D B P$ diastolic blood pressure, GLU glucose, TC total cholesterol, TG triglycerides, HDL-C high-density lipoprotein cholesterol, $L D L-C$ low-density lipoprotein cholesterol, UA uric acid. P: All participants had the variables analyzed by one-way ANOVA or Chi- square test among CNT, HT and HTO groups.*: $p<0.05$ vs. CNT.\# : $p<0.05$ vs. HT 
groups $(P>0.05)$. The TG level was significantly higher in the HTO group than that in the CNT and HT group. The UA levels in the HTO group were higher than those in the HT group.

\section{Comparison of plasma levels of ERBB3 among the three groups}

There were no statistically significant differences in ERBB3 levels among the three groups. By gender subgroup, the plasma concentrations of ERBB3 showed a linear decrease in the CNT, HT and HTO groups in men $(1.13 \pm 0.36,1.03 \pm 0.36$, and $0.84 \pm 0.26 \mathrm{ng} / \mathrm{mL}$, respectively; $P=0.007)$. In the subgroup of alcohol drinkers, the ERBB3 level was significantly decreased in the HTO group as compared with those of the CNT and HT groups $(0.76 \pm 0.23$ versus $1.18 \pm 0.37$ and $1.20 \pm 0.30$, respectively) (Table 2).

\section{Correlation of plasma ERBB3 levels and clinical characteristics}

Table 3 summarises the Pearson correlation coefficients between ERBB3 levels and hypertension risk factors stratified by sex, smoking, and drinking. ERBB3 levels were negatively correlated with DBP in men $(r=-0.293$, $P=0.012)$, smoking $(r=-0.47, P=0.004)$, and drinking $(r=-0.387, P=0.008)$. Notably, BMI also correlated negatively with ERBB3 levels among men and drinkers. Similarly, UA levels were negatively correlated with ERBB3 levels among drinkers (all $P<0.05$ ).

\section{Multinomial logistic regression}

Table 4 shows the associations of HT and HTO with increasing levels of ERBB3 within subgroups of sex, current smoking, and drinking. Plasma ERBB3 levels were negatively associated with hypertension and overweight among men (OR 0.054, $95 \%$ CI 0.0070.412 ) and drinking (OR 0.002, $95 \%$ CI 0.000-0.101). After adjusting for age and sex, the association remained significant.

\section{Discussion}

The Framingham Study showed that hypertension [18] and overweight [19] are both independent risk factors for cardiovascular disease, and approximately $30 \%$ of hypertensive individuals can be classified as obese [20]. In addition, ERBB3 has been reported to play an important role in the maintenance and development of cardiovascular disorders $[11,15]$. This study is the first to demonstrate the importance of ERBB3 levels in overweight patients with hypertension. We observed a negative association between ERBB3 levels and hypertension with overweight among only men and drinkers. These results indicate that ERBB3 levels might contribute to the development of hypertension in overweight individuals.

A previous animal study demonstrated that ERBB3 receptors might be involved in blood pressure regulation through NRG-1/ERBB signalling as an antihypertensive system, but that this effect is probably not that strong [21]. In this study, we observed a negative correlation between ERBB3 and DBP in the male, drinking and smoking groups. A previous reports suggested that males are generally at greater risk for hypertension than age-matched females [22]. Another study reported that environmental exposure to drinking and smoking was associated with adult hypertension in the Japanese population [23]. Remarkably, DBP showed increased sensitivity to environmental changes, and more strongly predicted cardiovascular disease risk in younger Chinese adults [24]. In the present study, BMI (both in men and in the drinking population) and UA (among drinkers) correlated negatively with ERBB3 levels. Other studies found men are more frequently overweight, and consume more alcohol than women [25]. Additionally, genetic studies have shown that ERBB3 is responsible for variations in the LDL-C serum concentration, and plays a role in lipid homeostasis and obesity [26]. Taken together, BMI, gender, and drinking all potentially modulate the association between ERBB3 levels and hypertension in overweight individuals.

Table 2 Stratification analyses for comparison plasma levels of ERBB3 among the three groups

\begin{tabular}{|c|c|c|c|c|c|c|}
\hline Characteristic & Group & CNT $(n=31)$ & HT $(n=33)$ & HTO $(n=64)$ & $F$ & $P$ \\
\hline Total population & & $1.00 \pm 0.43$ & $1.01 \pm 0.35$ & $0.92 \pm 0.37$ & 0.792 & 0.455 \\
\hline \multirow[t]{2}{*}{ Gender } & Male & $1.13 \pm 0.36$ & $1.03 \pm 0.36$ & $0.84 \pm 0.26^{*} \#$ & 5.265 & 0.007 \\
\hline & Female & $0.82 \pm 0.47$ & $0.97 \pm 0.34$ & $1.00 \pm 0.43$ & 0.816 & 0.448 \\
\hline \multirow[t]{2}{*}{ Current smoker } & Yes & $1.20 \pm 0.41$ & $1.06 \pm 0.40$ & $0.89 \pm 0.30$ & 1.770 & 0.186 \\
\hline & No & $0.88 \pm 0.40$ & $0.97 \pm 0.31$ & $0.93 \pm 0.38$ & 0.284 & 0.753 \\
\hline \multirow[t]{2}{*}{ Current drinker } & Yes & $1.18 \pm 0.37$ & $1.20 \pm 0.30$ & $0.76 \pm 0.23^{*} \#$ & 12.483 & $<0.001$ \\
\hline & No & $0.89 \pm 0.44$ & $0.90 \pm 0.33$ & $1.00 \pm 0.40$ & 0.810 & 0.449 \\
\hline
\end{tabular}

CNT healthy control group, HT hypertension group, HTO hypertension with overweight group. P: All participants had the variables analyzed by one-way ANOVA or Chi- square test among CNT, HT and HTO groups.*: $p<0.05$ vs. CNT.\# : $p<0.05$ vs. HT.*: $p<0.05$ vs. Control.\# : $p<0.05$ vs. hypertension 
Table 3 Correlation of plasma ERBB3 levels and clinical characteristics by gender, smoking, and drinking

\begin{tabular}{|c|c|c|c|c|c|c|c|c|c|c|c|c|c|c|}
\hline \multirow[t]{2}{*}{ Characteristic } & \multicolumn{2}{|l|}{ Male } & \multicolumn{2}{|c|}{ Female } & \multicolumn{2}{|c|}{ Nonsmoking } & \multicolumn{2}{|c|}{ Smoking } & \multicolumn{2}{|c|}{ Nondrinking } & \multicolumn{2}{|c|}{ Drinking } & \multicolumn{2}{|c|}{ Total population } \\
\hline & $r$ & $P$ & $r$ & $P$ & $r$ & $P$ & $r$ & $P$ & $r$ & $P$ & $r$ & $P$ & $r$ & $P$ \\
\hline $\mathrm{SBP}(\mathrm{mmHg})$ & -0.155 & 0.193 & 0.038 & 0.779 & 0.019 & 0.855 & -0.194 & 0.256 & 0.022 & 0.846 & -0.239 & 0.109 & -0.062 & 0.49 \\
\hline $\mathrm{DBP}(\mathrm{mmHg})$ & -0.293 & 0.012 & 0.019 & 0.89 & -0.011 & 0.914 & -0.47 & 0.004 & -0.03 & 0.788 & -0.387 & 0.008 & -0.129 & 0.146 \\
\hline $\mathrm{TC}(\mathrm{mmol} / \mathrm{L})$ & 0.07 & 0.562 & -0.094 & 0.491 & 0.048 & 0.647 & -0.053 & 0.76 & -0.05 & 0.655 & 0.071 & 0.637 & -0.003 & 0.971 \\
\hline $\mathrm{TG}(\mathrm{mmol} / \mathrm{L})$ & 0.014 & 0.907 & 0.138 & 0.31 & 0.149 & 0.157 & -0.11 & 0.521 & 0.117 & 0.293 & -0.001 & 0.995 & 0.079 & 0.376 \\
\hline $\mathrm{HDL}-\mathrm{C}(\mathrm{mmol} / \mathrm{L})$ & 0.031 & 0.795 & 0.03 & 0.826 & 0.045 & 0.669 & 0.113 & 0.511 & 0.044 & 0.691 & -0.009 & 0.953 & 0.023 & 0.794 \\
\hline LDL-C(mmol/L) & 0.068 & 0.57 & -0.202 & 0.136 & -0.054 & 0.612 & -0.059 & 0.733 & -0.151 & 0.176 & 0.088 & 0.563 & -0.057 & 0.526 \\
\hline Glu(mmol/L) & 0.034 & 0.776 & 0.117 & 0.39 & 0.156 & 0.138 & -0.095 & 0.582 & 0.015 & 0.894 & 0.214 & 0.153 & 0.077 & 0.391 \\
\hline UA(umol/L) & -0.169 & 0.156 & 0.081 & 0.551 & -0.047 & 0.66 & -0.075 & 0.663 & 0.08 & 0.475 & -0.375 & 0.01 & -0.041 & 0.647 \\
\hline BMI(kg/m2) & -0.252 & 0.034 & 0.089 & 0.516 & -0.017 & 0.872 & -0.173 & 0.321 & 0.065 & 0.561 & -0.389 & 0.008 & -0.079 & 0.378 \\
\hline
\end{tabular}

CNT healthy control group, HT hypertension group, HTO hypertension with overweight group, BMI body mass index, SBP systolic blood pressure, DBP diastolic blood pressure, GLU glucose, TC total cholesterol, TG triglycerides, HDL-C high-density lipoprotein cholesterol, $L D L-C$ low-density lipoprotein cholesterol, UA uric acid

However, the mechanisms that link ERBB3 and hypertension and overweight are currently unclear. Previous studies have explored potential mechanisms linking adiposity and high blood pressure, including sympathetic nervous system activation, activation of the renin-angiotensin system, inflammatory responses, and insulin resistance [27]. It may be speculated that ERBB3 participates in several networks related to lipid metabolism which is a major variable in the aetiology of both overweight and hypertension [28]. In addition, ERBB3 participates in neutrophil survival and ERBB3 inhibitors play positive roles in accelerating inflammation resolution [29], which is a known predisposing factor for the development and progression of hypertension and overweight. Signalling interactions have been reported between ERBB3 family members and insulin-like growth factor-1 receptor (IGF-IR) [30]. Our group previously reported that IGF-IR may contribute to the genetic susceptibility to hypertension [31], and higher IGF-IR mRNA expression levels were observed in obese children [32]. Thus, it is reasonable to consider that the plasma ERBB3 levels might play an important role in the regulation of hypertension in overweight by affecting IGF-IR.

There are a few limitations to our study. Firstly, the potential bias in cross-sectional studies can often distort the results of epidemiological associations. Secondly, no significant differences in plasma ERBB3 levels were observed among the three groups in the total population, despite the fact that strict standards were used to select representative cases and controls. The relatively small sample size may have led to weak statistical power. Thus, further prospective studies are required to confirm these observations and to increase the sample size. In particular, more research involving the obese population is warranted.

\section{Conclusions}

In summary, our results provide the first demonstration that the expression of ERBB3 was significantly downregulated in overweight individuals with hypertension, and that BMI, gender, and drinking all potentially modulate the process. Further larger studies may help to elucidate the relationship and role of ERBB3 levels in the pathogenesis of hypertension in overweight individuals.

Table 4 Multinomial logistic regression analysis between ERBB3 and HT and HTO by gender, smoking, and drinking

\begin{tabular}{|c|c|c|c|c|c|}
\hline \multirow[t]{2}{*}{ Characteristic } & \multirow[t]{2}{*}{ Group } & \multicolumn{2}{|l|}{ Mode1 } & \multicolumn{2}{|l|}{ Mode2 } \\
\hline & & $\mathrm{HT}(\mathrm{n}=33)$ & $\mathrm{HTO}(\mathrm{n}=64)$ & $\mathrm{HT}(\mathrm{n}=33)$ & $\mathrm{HTO}(\mathrm{n}=64)$ \\
\hline \multirow[t]{2}{*}{ Gender } & Male & $0.414(0.064-2.685)$ & $0.054(0.007-0.412)$ & $0.401(0.060-2.707)$ & $0.059(0.008-0.437)$ \\
\hline & Female & $3.007(0.305-29.645)$ & $3.612(0.495-26.354)$ & $2.589(0.274-24.448)$ & $2.997(0.426-21.077)$ \\
\hline \multirow[t]{2}{*}{ Current smoker } & Yes & $0.379(0.046-3.146)$ & $0.096(0.007-1.250)$ & $0.368(0.043-3.179)$ & $0.100(0.008-1.284)$ \\
\hline & No & $2.006(0.332-12.113)$ & $1.503(0.315-7.180)$ & $1.843(0.305-11.139)$ & $1.433(0.315-6.527)$ \\
\hline \multirow[t]{2}{*}{ Current drinker } & Yes & $1.221(0.106-14.070)$ & $0.002(0.000-0.101)$ & $1.354(0.108-16.981)$ & $0.002(0.000-0.111)$ \\
\hline & No & $1.077(0.177-6.537)$ & $2.242(0.481-10.458)$ & $0.877(0.133-5.784)$ & $2.036(0.439-9.436)$ \\
\hline
\end{tabular}




\section{Abbreviations}

CNT: Healthy control group; HT: Hypertension group; HTO: Hypertension with overweight group; BMI: Body mass index; SBP: Systolic blood pressure; DBP: Diastolic blood pressure; ELISA: Enzyme-linked immunosorbent assay; GLU: Glucose; TC: Total cholesterol; TG: Triglycerides; HDL-C: High-density lipoprotein cholesterol; LDL-C: Low-density lipoprotein cholesterol; UA: Uric acid

\section{Acknowledgements}

The authors would like to thank all the participants in this study.

\section{Authors' contributions}

LJZ and ZMF conducted the experiments. LJZ managed and analyzed the data and wrote the manuscript. MYH was one of the principal investigators of the study. YLJ revised the manuscript. WWC was a contributor in organizing the database. YC and YSY reviewed the manuscript. All authors read and approved the final manuscript.

\section{Funding}

This research was supported by the National Natural Science Foundation of China (No. 81874280 and No. 81673266); The Fifth Batch of Talents Selected under the Special Support Plan in Anhui Provence(Organization Department of Anhui provincial Party committee,[2019]No.14); Anhui Provincial Natural Science Foundation (No. 1808085QH283 and No. 1808085MH297); Key Projects of Anhui Provincial Department of Education (No. KJ2019A0404 and No. KJ2019A0405). These funding agencies did not influence the study design, data collection and analysis, decision to publish, or preparation of the manuscript.

\section{Availability of data and materials}

The datasets during and/or analyzed during the current study will be available from the corresponding author on reasonable request.

\section{Declarations}

\section{Ethics approval and consent to participate}

The study was approved by the Ethics Committee of the First Affiliated Yijishan Hospital of Wannan Medical College (Wuhu,China).Written informed consent was obtained from each participant.

\section{Consent for publication}

Not applicable.

\section{Competing interests}

The authors declare no conflict of interest.

\section{Author details}

'Department of Epidemiology and Biostatistics, School of Public Health, Wannan Medical College, No. 22, Wenchang Road, Anhui 241002 Wuhu, China. ${ }^{2}$ Institute of Chronic Disease Prevention and Control,Wannan Medical College, No. 22, Wenchang Road, Anhui 241002 Wuhu, China. ${ }^{3}$ Department of Medicine, Anhui College of Traditional Chinese Medicine, No.18, Wuxia Shanxi Road, Anhui 241003 Wuhu, China.

Received: 17 September 2020 Accepted: 15 June 2021

Published online: 27 June 2021

\section{References}

1. Lewington S, Lacey B, Clarke R, Guo Y, Kong XL, Yang L, Chen Y, Bian Z, Chen J, Meng J, Xiong Y, He T, Pang Z, Zhang S, Collins R, Peto R, Li L, Chen Z. China Kadoorie Biobank C. (2016) The Burden of Hypertension and Associated Risk for Cardiovascular Mortality in China. JAMA Intern Med 176: 524-32. https://doi.org/10.1001/jamainternmed.2016.0190.

2. Collaboration NCDRF. Worldwide trends in blood pressure from 1975 to 2015: a pooled analysis of 1479 population-based measurement studies with 19.1 million participants. Lancet. 2017;389:37-55. https://doi.org/10.101 6/S0140-6736(16)31919-5.

3. Hu ST, Gao RL, Liu LS, Zhu ML, Wang W, Wang YJ, Wu ZS, Li HJ, Gu DF, Yang YJ, Zheng Z, Cheng WW. Summary of report on cardiovascular diseases in China (2018). Chin Circ J. 2019;34:209-20.
4. Cutler JA, Sorlie PD, Wolz M, Thom T, Fields LE, Roccella EJ. Trends in hypertension prevalence, awareness, treatment, and control rates in United States adults between 1988-1994 and 1999-2004. Hypertension. 2008;52:818-27. https://doi.org/10.1161/HYPERTENSIONA HA.108.113357.

5. Wilson PW, D'Agostino RB, Sullivan L, Parise H, Kannel WB. Overweight and obesity as determinants of cardiovascular risk: the Framingham experience. Arch Intern Med. 2002;162:1867-72. https://doi.org/10.1001/archinte.162.16.1 867.

6. Ma J, Wang Z, Dong B, Song Y, Hu P, Zhang B. Quantifying the relationships of blood pressure with weight, height and body mass index in Chinese children and adolescents. J Paediatr Child Health. 2012;48:413-8. https://doi. org/10.1111/j.1440-1754.2011.02221.x.

7. Feng RN, Zhao C, Wang C, Niu YC, Li K, Guo FC, Li ST, Sun CH, Li Y. BMI is strongly associated with hypertension, and waist circumference is strongly associated with type 2 diabetes and dyslipidemia, in northern Chinese adults. J Epidemiol. 2012;22:317-23. https://doi.org/10.2188/jea.je20110120.

8. Linhart C, Tukana I, Lin S, Taylor R, Morrell S, Vatucawaqa P, Magliano D, Zimmet P. Continued increases in hypertension over three decades in Fiji, and the influence of obesity. J Hypertens. 2016;34:402-9. https://doi.org/10.1 097/HJH.0000000000000807. discussion 409.

9. Yarden Y, Sliwkowski MX. Untangling the ErbB signalling network. Nat Rev Mol Cell Biol. 2001;2:127-37. https://doi.org/10.1038/35052073.

10. Shi F, Telesco SE, Liu Y, Radhakrishnan R, Lemmon MA. Erbb3/her3 intracellular domain is competent to bind atp and catalyze autophosphorylation. Proc Natl Acad Sci U S A. 2010;107:7692-7. https://doi. org/10.1073/pnas.1002753107.

11. Hedhli N, Kalinowski A and Russell KS. Cardiovascular effects of neuregulin1/ErbB signaling: role in vascular signaling and angiogenesis. Curr Pharm Des. 2014:20:4899-905. https://doi.org/10.2174/1381612819666131125151 058.

12. Ryzhov S, Matafonov A, Galindo CL, Zhang Q, Tran TL, Lenihan DJ, Lenneman CG, Feoktistov I, Sawyer DB. ERBB signaling attenuates proinflammatory activation of nonclassical monocytes. Am J Physiol Heart Circ Physiol. 2017;312:H907-18. https://doi.org/10.1152/ajpheart.00486.2016.

13. Wang GX, Zhao XY, Meng ZX, Kern M, Dietrich A, Chen Z, Cozacov Z, Zhou D, Okunade AL, Su X, Li S, Bluher M, Lin JD. The brown fat-enriched secreted factor Nrg4 preserves metabolic homeostasis through attenuation of hepatic lipogenesis. Nat Med. 2014;20:1436-43. https://doi.org/10.1038/ $\mathrm{nm} .3713$

14. Akhtar S, Chandrasekhar B, Attur S, Dhaunsi GS, Yousif MH, Benter IF. Transactivation of ErbB Family of Receptor Tyrosine Kinases Is Inhibited by Angiotensin-(1-7) via Its Mas Receptor. PLoS One. 2015;10:e0141657. https:// doi.org/10.1371/journal.pone.0141657

15. Maitusong B, Xie X, Ma YT, Fu ZY, Yang YN, Li XM, Liu F, Chen BD, Gai MT. Association between ErbB3 genetic polymorphisms and coronary artery disease in the Han and Uyghur populations of China. Int J Clin Exp Med. 2015;8:16520-7.

16. Ottolini M, Hong K, Cope EL, Daneva Z, DeLalio LJ, Sokolowski JD, Marziano C, Nguyen NY, Altschmied J, Haendeler J, Johnstone SR, Kalani MY, Park MS, Patel RP, Liedtke W, Isakson BE, Sonkusare SK. Local Peroxynitrite Impairs Endothelial Transient Receptor Potential Vanilloid 4 Channels and Elevates Blood Pressure in Obesity. Circulation. 2020;141:1318-33. https://doi.org/1 0.1161/CIRCULATIONAHA.119.043385.

17. Saifeddine M, El-Daly M, Mihara K, Bunnett NW, Mclntyre P, Altier C Hollenberg MD, Ramachandran R. GPCR-mediated EGF receptor transactivation regulates TRPV4 action in the vasculature. Br J Pharmacol. 2015:172:2493-506. https://doi.org/10.1111/bph.13072.

18. Kannel WB. Blood pressure as a cardiovascular risk factor: prevention and treatment. JAMA. 1996:275:1571-6.

19. Hubert HB, Feinleib M, McNamara PM, Castelli WP. Obesity as an independent risk factor for cardiovascular disease: a 26-year follow-up of participants in the Framingham Heart Study. Circulation. 1983;67:968-77. https://doi.org/10.1161/01.cir.67.5.968.

20. MacMahon S, Cutler J, Brittain E, Higgins M. Obesity and hypertension: epidemiological and clinical issues. Eur Heart J. 1987;8(Suppl B):57-70. https://doi.org/10.1093/eurheartj/8.suppl_b.57.

21. Matsukawa R, Hirooka $Y$, Nishihara M, Ito K, Sunagawa K. Neuregulin-1/ErbB signaling in rostral ventrolateral medulla is involved in blood pressure regulation as an antihypertensive system. J Hypertens. 2011;29:1735-42. https://doi.org/10.1097/HJH.0b013e32834937d6. 
22. Wiinberg N, Hoegholm A, Christensen HR, Bang LE, Mikkelsen KL, Nielsen PE, Svendsen TL, Kampmann JP, Madsen NH, Bentzon MW. 24-h ambulatory blood pressure in 352 normal Danish subjects, related to age and gender. Am J Hypertens. 1995;8:978-86. https://doi.org/10.1016/0895-7061(95)0021 6-2.

23. Shive I. Self and environmental exposures to drinking, smoking, gambling or video game addiction are associated with adult hypertension, heart and cerebrovascular diseases, allergy, self-rated health and happiness: Japanese General Social Survey, 2010. Int J Cardiol. 2015;181:403-12. https://doi.org/1 0.1016/j.ijcard.2014.12.071.

24. Attard SM, Herring AH, Zhang B, Du S, Popkin BM, Gordon-Larsen P. Associations between age, cohort, and urbanization with SBP and DBP in China: a population-based study across 18 years. J Hypertens. 2015;33:94856. https://doi.org/10.1097/HJH.0000000000000522.

25. Freedman DS, Jacobsen SJ, Barboriak JJ, Sobocinski KA, Anderson AJ, Kissebah AH, Sasse EA, Gruchow HW. Body fat distribution and male/female differences in lipids and lipoproteins. Circulation. 1990;81:1498-506. https:// doi.org/10.1161/01.cir.81.5.1498.

26. Cox LA, Birnbaum S, VandeBerg JL. Identification of candidate genes regulating $\mathrm{HDL}$ cholesterol using a chromosomal region expression array. Genome Res. 2002;12:1693-702. https://doi.org/10.1101/gr.333502.

27. Rahmouni K. Obesity-associated hypertension: recent progress in deciphering the pathogenesis. Hypertension. 2014;64:215-21. https://doi. org/10.1161/HYPERTENSIONAHA.114.00920.

28. Zou ZY, Yang YD, Wang S, Dong B, Li XH, Ma J. The importance of blood lipids in the association between BMl and blood pressure among Chinese overweight and obese children. Br J Nutr. 2016;116:45-51. https://doi.org/1 $0.1017 / 50007114516001744$.

29. Rahman A, Henry KM, Herman KD, Thompson AA, Isles HM, Tulotta C, Sammut D, Rougeot JJ, Khoshaein N, Reese AE, Higgins K, Tabor C, Sabroe I, Zuercher WJ, Savage CO, Meijer AH, Whyte MK, Dockrell DH, Renshaw SA, Prince LR. Inhibition of ErbB kinase signalling promotes resolution of neutrophilic inflammation. Elife. 2019;8. https://doi.org/10.7554/eLife.50990.

30. Jin Q, Esteva FJ. Cross-talk between the ErbB/HER family and the type I insulin-like growth factor receptor signaling pathway in breast cancer. J Mammary Gland Biol Neoplasia. 2008;13:485-98. https://doi.org/10.1007/s1 0911-008-9107-3.

31. Yao Y, Zhu L, Fang Z, Yang S, Chen Y, Jin Y, Zhao X, Zhao H, Zhuang $Q$, Chen X, Shen C. Insulin-Like Growth Factor-1 and Receptor Contribute Genetic Susceptibility to Hypertension in a Han Chinese Population. Am J Hypertens. 2018;31:422-30. https://doi.org/10.1093/ajh/hpx195.

32. Ricco RC, Ricco RG, Queluz MC, de Paula MTS, Atique PV, Custodio RJ, Tourinho Filho H, Del Roio Liberatori R Jr, Martinelli CE Jr. IGF-1R mRNA expression is increased in obese children. Growth Horm IGF Res. 2018:39:1-5. https:/doi.org/10.1016/j.ghir.2017.11.001.

\section{Publisher's Note}

Springer Nature remains neutral with regard to jurisdictional claims in published maps and institutional affiliations.

\section{Ready to submit your research? Choose BMC and benefit from:}

- fast, convenient online submission

- thorough peer review by experienced researchers in your field

- rapid publication on acceptance

- support for research data, including large and complex data types

- gold Open Access which fosters wider collaboration and increased citations

- maximum visibility for your research: over $100 \mathrm{M}$ website views per year

At $\mathrm{BMC}$, research is always in progress.

Learn more biomedcentral.com/submissions 